\section{Equity Matters}

Since our last issue, the world has lost two eminent public health researchers and practitioners, both of whose work has been inspirational to us at MEDICC Review. Dr Gustavo Kourí Flores was a Cuban physician who directed the Pedro Kouri Tropical Medicine Institute in Havana, a WHO Collaborating Center, for more than three decades. Dr Barbara Starfield was a leader in research on health inequalities and a powerful advocate for primary health care. Both will continue to influence public health through their legacies in research, teaching, and practice.

This year, the world's population reaches seven billion, one of seven people living on the margins of survival; 100 million annually are pushed into poverty by health care costs alone.

The latest World Health Report and the Final Report from the WHO Commission on Social Determinants of Health call on all governments to universalize health care coverage. The Commission recognizes health systems as social determinants in their own right, their goals and achievements determined by political commitment to population health, the poor in particular. In achieving good health for all, equity does indeed matter, but as articles in this issue indicate, its pursuit is multidimensional and fraught with contradictions.

The first dimension we explore is the foundation of primary health care. From the Alma-Ata Declaration to the present, as Dr Starfield has noted, primary health care is an indispensable 'equityproducing social policy.'[1] Two articles in this issue describe innovations in primary health care, one to ensure optimal care for a vulnerable group in a system that is already universal: Maternity Homes in Cuba: Evolution of a Model to Address At-Risk Pregnancy by senior editor Gorry. The other refers to successes of a national effort to extend primary health care: Ethiopia's Health Extension Program: Improving Health through Community Involvement by Banteyerga.

The second dimension is community involvement in prioritysetting and research: Loewenson and colleagues share results from four countries in Raising the Profile of Participatory Action Research at the 2010 Global Symposium on Health Systems Research and Hermida comments on the incorporation of heretofore unheeded voices in his country's health policy, and indeed the entire collective social endeavor (Sumak Kawsay: Ecuador Builds a New Health Paradigm).

Another vital dimension to promote health equity is achieving the right mix, quality and placement of human resources for health, ensuring social accountability of health sciences education. We are pleased to update our 2008 exchange with a number of deans of schools involved in the innovative Training for Health Equity Network (THEnet) in Roundtable: Revisiting Innovative Leaders in Medical Education by THEnet coordinators Neusy and Palsdottir.

The fourth dimension reviewed is the role of research and strategy assessment in policy setting, overhaul, and readjustment, in Le and Blum's Intentional Injury in Young People in Vietnam: Prevalence and Social Correlates and Cuba's Strategy for Childhood Tuberculosis Control, 1995-2005 by Abreu et al.
The contradictions in achieving equity begin to emerge around the issue of resource allocation to fulfill the interests and needs of specific groups.

The first conflict that looms is between the policy goal of health for all and the pursuits of corporate interests, regulatory agencies, and other stakeholders. How this plays out in practice is discussed by Lage in Global Pharmaceutical Development and Access: Critical Issues of Ethics and Equity and by Higashi et al. in Population-Level Approaches to Universal Health Coverage in Resource-Poor Settings: Lessons from Tobacco Control Policy in Vietnam.

"When we look at the
health sector, we find some
good evidence that fairness
is a priority for the inter-
national community, that
equity matters, and that
the health sector is a prime
entry point for its pursuit."
Margaret Chan
Director General, WHO

The second dilemma is related to tensions between universality and the need for special efforts to target the needs of vulnerable populations. In fact, as stressed in the Social Determinants of Health Final Report, both strategies should be pursued simultaneously. But, as two articles in this issue indicate, this is easier said than done (Impact of Court Rulings on Health Care Coverage: The Case of HIVIAIDS in Colombia by González and Durán, and Making the Right to Health a Reality for Brazil's Indigenous Peoples: Innovation Cycles, Decentralization and Equity by Coelho and Shankland).

One aspect certainly warranting further discussion is the extent to which health care in any country is considerd a common good or simply a commodity subject to packaging, as in many programs defining the extent of coverage, especially for poor people without the means to contribute to insurance schemes.

Finally, Abimbola's Health Systems in an Interconnected World: A View from Nigeria advises humility and 'avoiding blindness born of superiority or inferiority complexes' to pursue a mutual learning process as all nations reach for universal health care and equity.

We hope that this issue's 19 authors representing experiences of as many countries offer a contribution to this global quest.

Our thanks to the organizers of the First Global Symposium on Health Systems Research, from which a number of this issue's papers emerged, and to The Rockefeller Foundation and The Atlantic Philanthropies for their generous financial support. - 1/p

\section{The Editors}

1. Starfield B. Politics, primary healthcare and health: was Virchow right? J Epidemiol Community Health. 2011;65(8):653-5. 